\title{
Green economy for sustainable environment: Slovenian perspective
}

Abstract

Sustainable development of built environment is necessary much more than in the past, but a very stringent monitoring of environmental impacts is needed to get economic balance and social acceptance of the constructions. Green economy generates new jobs and the new culture, but rellable assessment of net green revenues is still lacking. Moreover, construction sector faces with more than $50 \%$ of waste generated in total scale, $40 \%$ of all consumed energy, and $35 \%$ of $\mathrm{CO} 2$ released emissions. This study aims to provide more insights in green sectors, and the evaluation of sustainability. Green public protal, economic, and social aspects are harmonized.

\section{Introduction}

A "green" economy (smart energy \& environment) generates jobs, businesses and investments while expanding clean energy production, increasing energy efficiency, reducing greenhouse gas emissions, waste and pollution, and conserving water and other natural resources. The "green" or "cle$\mathrm{an}^{\prime}$ or low-carbon economy - defined as the sector of the economy that produces goods and services with an environmental benefit - remains at once a compelling aspiration and an enigma. As a matter of aspiration, no swath of the economy has been more widely celebrated as a source of economic renewal and potential job creation. The green economy offers enormous opportunities for job creation, many of which are already underway in the European economy. These opportunities range from sectors traditionally associted with an environmental content - such as renewabse ened with recycling - to other activities that represent emerging sectors in green jobs - such as suest that resility - and to activities in "establis - such as ustich have potential for converies into subtain into sustainable activites. The importance of emerging green ght to the Europen region. Recent estims by the Ecourght to the European region. Recent estimates by the Eco-Innovation Observatory [1] show that exports of environmental goods and services increased nearly three-fold since 1999, to over 35 billion $€$ in 2016. The EU has devoted more public research resources to environmental-related sciences than any other research system in the world. Between 2006 and 2016 the number of eco-industries sectors' workers increased by $70 \%$, approximately 3,4 million people, and produced $64 \%$ more in turnover, with a total turnover estimated to be more than 300 billion $€$. Many European companies are implementing eco-innovation and around $27 \%$ of innovating companies in the EU have increased their material efficiency as a result of implemented changes [2]. However, there is still a gap between the potential for eco-innovation and the cur- rent state of eco-innovation activity in the EU. According to the data available, there are about 7.360.000 jobs in the EU in green sectors (renewable energies, energy efficiency, retrofitting, organic agriculture, waste management and recycling). The renewable energy sector employs more than 1.114 .000 people in the EU-27. The eco-industry provides between 2,9-3,6 million jobs. The European insulation industry alone represented 232.050 full time jobs in 2009 in house retrofitting projects. The railway sector totted up 900,000 jobs across Europe in the transport of goods and passengers. Another relevant figure is the number of urban public transport jobs, around 900,000 in EU-25. The employment associted with waste manament and recycling sectors reached 2 million jectors producers inked to organic farming. A high podent for the potentian for the new $(26,7 \%)$ follow by architure and fivily$(26,7 \%)$ followed by architecture and civil engineering $(23,4 \%)$ where sustainable construction is one of the six priorities [1]. Sustainable construction is at the heart of moder construction, and refers to all aspects of this branch of industry: the environmental aspect, which includes energy efficiency, the financial aspect, and the sociological aspect, while not forgetting the technical aspects of sustainable construction [3]. Moreover, eco-innovatio present means to reach a resource-efficient and circular economy in Europe.

Yet, the green economy remains an enigma: hard to assess. Not only do "green" or "clean" activities and jobs related to environmental aims pervade all define and isolate - and count. The clean economy has remained elusive in part because, in the absence of standard definitions and data, strikingly little is known about its nature, size and growth at the critical regional level. Currently no comprehensive national database exists on the spatial geography of the clean economy and its sub industries, although importan work has assed the clean oconomy across state. And while work has assessed the clean economy across state. And while numerous stries, a proliferation of definitions and the ab or ce of da for large numbers of regions have made it difficut ce of dita forlicicult o situate regional clean economies in a national and comparative context. Our study provides more insights into the genenic

\section{Green economy with sustainable environment}

The European Union's new strategy for sustainable growt and jobs, Europe 2020, puts innovation and green growth at the heart of its blueprint for competitiveness. However, the re are no explicit overarching national strategies targeting green skills needs [4]. Some Member States are moving faster than others to rectify this, with France launching its recent mobilization plan for green jobs, and the UK governmen recently launching a consultation exercise, entitled Meetin the low carbon skills challenge. The EU suffers from systemic weaknesses in its skills base which limit its productivity and competitiveness in today's economy, and reduce its capacity to exploit the opportunities offered by green growth. These deficits in management skills and technical job-specific skills (many of which are related to science, technology, engineering and mathematics) are a greater concern than shortages of "new" green skills [4].

To answer the question, where green jobs can really help to reduce unemployment, it is necessary to take into account the net rather than gross effects of green jobs employment. Gross effects are a useful indicator of where we want to dethis case greening) econy helps to reduce the number in case gre un coll the jobs created without pay jobs becau the unt of all the jobs created without pay jobs because of these hew have to mention that the interpretation of the effects on employment are not clear itself, it can make a huge impact on employment may also lead to low productivity. The net ef fect on employment is calculated by dividing the gross effect added to the substitution effect and the income effect. The substitution effect reflects the fact that this green goods and green substitutes other (conventional) goods and services. The income effect into account the fact that the "green goods and services" more expensive than conventional goods and services. If people buy such goods and services, they are left with less money to buy other goods. Of course, the income effect depends on the source of funding and disappears when state-funded greening the economy by increa- sing debt, because it means that aggregate finance the greening of the economy by the state through an increase in debt resulted in a much better net impact on employment and lower unemployment. If we look at the net effects on employment for each country, it is of course necessary to add the effects of imports and exports.

There are many ways to define "green" or the "green economy". The following definitions "re only a sampling of the many definitions are concepts are evident in each of these deficitions. For example, the words renewable,

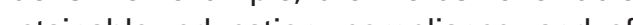
ficiency a e used by all orgaizalond The world stronges/ most compative ens. The of USA [5] defins grempetitive economy s [6] [5] detines green economy activity at least one of the following: (1) Generating and storing renewable energy; (2) Recycling existing materials; (3) Energy efficient product manufacturing, distribution, construction, installation, and maintenance; (4) Education, compliance and awareness, and (5) Natural and sustainable product manufacturing. Especially important is energy efficient product manufacturing, distribution, construction, installation, and maintenance - This includes companies involved in the research, development, and manufacturing of products such as solar panels, energy efficient devices, infrastructure and vehicles. It also includes construction companies that install and repair these products in new or existing residentia or commercial real estate, as well as real estate planning and land development to generte green jobs. A Green Job is an occupation rers with policies, informaion, materis, and/or technologies that contibute to miniming impact, and (2) requires specialized knowledge, skils, (2) requires experience in the areas whil a Greer is an orcenization the provides preducts and or services that provides products and urces more efficiently, providing renewable sources of energy, lowering greenhouse gas emissions, or otherwise minimizing environmental impact [6]

The United Nations Environmental Programme (UNEP) defines green jobs "... as work in agricultural, manufacturing, research and development (R\&D), administrative, and service activities that contribute substantially to preserving or restoring environmental quality [7]. International Labour Organization (ILO) 
indicates [8] that "Green jobs" does not lend itself to a tight definition but certainly includes the direct employment which reduces environmental impact ultimately to levels that are sustainable. This includes jobs that help to reduce the consumption of energy and raw materials, decarbonizes the economy, protect and restore ecosystems and biodiversity and minimize the production of waste and pollution. Green jobs are central to sustainable development and respond to the global challenges of environmental protection, economic development and social inclusion. By engaing governments, workers and employers as active agents of chane, the promotes the greening of enterprises, workpace practices prot the lobre and the labor markt as a whole. Th, werke eforts create decent enploymenoporunies, enhance resource eficiency and buld low-carbon sustainable societies [8]. The Eurostat methodology for the "Envionmental Goods and Services Sector" (EGSS) does not define "green jobs", but measures employment in the EGSS. The EGSS is a heterogeneous set of producers of technologies, goods and services that prevent or minimize pollution and minimize the use of natural resources. Thus, environmental activities are divided into two broad segments: environmental protection and resource management [9]. International Trade Union Confederation (ITUC) indicates that "A Green Job should be one which reduces environmental impacts of enterprises and economic sectors, while providing decent working and living conditions to all those involved in production and ensuring workers' and labor rights are respected" [7].

\subsection{Sustainable construction}

Modern European society is confronted with new challenges that are conditioned by climate change, rising energy dependence, limited natural resources, efforts for a healthy environment, and as much unspoiled nature as on the other hand, globalization and aging of the population. The latter can support the finding $50 \%$ of the sources of materials and natural deposits are for the needs of the building sector that over $50 \%$ of generated waste is generated in connection with bullings and that buildings consume around $40 \%$ final energy in the EU and a fina $\mathrm{CO} 2$ into the envind are of CO2 into the environment A lange part of the European economy is con\% an GDP and $78 \%$ of jobs in the EU [10]. European society requires the construction sector to contribute to maximizing the competitiveness of European industry. At the same time, it expects the construction sector to be able to provide better living and working conditions in a built environment. The company also demands that this environment is accessible to all, safe, lasting, pleasant, efficient and adaptable to changing requirements. At the same time, it must also be affordable. In 2005, in the framework of the European Construction Technology Platform (ECTP), the construction sector defined the vision of the development of the industry and developed strategic development Priority for the period up to 2030 . The vision of the ECTP 2030 foresees that the field of planning and construction will have to actively deal with the demands of a sustainable and competitive Europe. The vision describes the construction industry as an industry that is intensely oriented towards the customer or user, is a sustainable and on knowledge. It proposes two interlinked strategic goals for achieving the vision: (1) meeting the requirements and needs of the users (meeting clien requirements); (2) becoming sustainable [10] Sustainable cities have existed much longer than the sustainability discourse Sustainable investment practices much steer urbainable lopment When assessing various possibilies for susteribilities fork bution to ener savings that could be by cities, their buildings and their citizens. To by cities, their buildings and their citizens. To leave it here would how rowly defined sustainability agenda that neglects other dimensions than the "green" ones. In fact, it can be argued that social and economic sustainability issues show more resonance with property investors than that of the older type of environmental-energy sustainability [11]. Sustainability in smart construction comprises three dimensions, e.g. ecological sociological and economic. Sustainability issues above do not readily fit in to the definitions of the three sustainability dimensions, but are rather combinations of them. Figure 1 synthesis the various facets of the problem area. New business culture makes the profit reinvestment from 3 (economic) into 1 (ecological) and 2 (social) while new other culture keeps the inhabitants happy / satisfied when we maintain 1 (ecological) and 3 (economic). A need for technical solutions, e.g passive houses, smart houses, remains. The role fo the housing houses, remains. The role for buildings and infet is twofold

Along with ecology, economics and socio-culAlon socio-culpol critional but very im

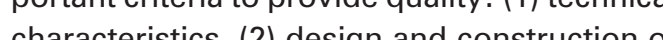
the building and (3) party the location teristics of and (3) parly the location characteristics of the building. It seem to be decisive for quality, so that sustainability buildings can be described and evaluated using five dimensions of quality: (1) eco quality, (2) economic quality, (3) socio-cultural functional quality, (4) technical quality, (5) process quality, and (6) quality of location. Different aspects of sustainability they are, inter alia, in the direct interaction, so it is indispensable overall assessment [12].

With regard to circular economy aspects embedded in green economy, performance across the EU MS is very heterogeneous. Countries differ widely with regard to investments

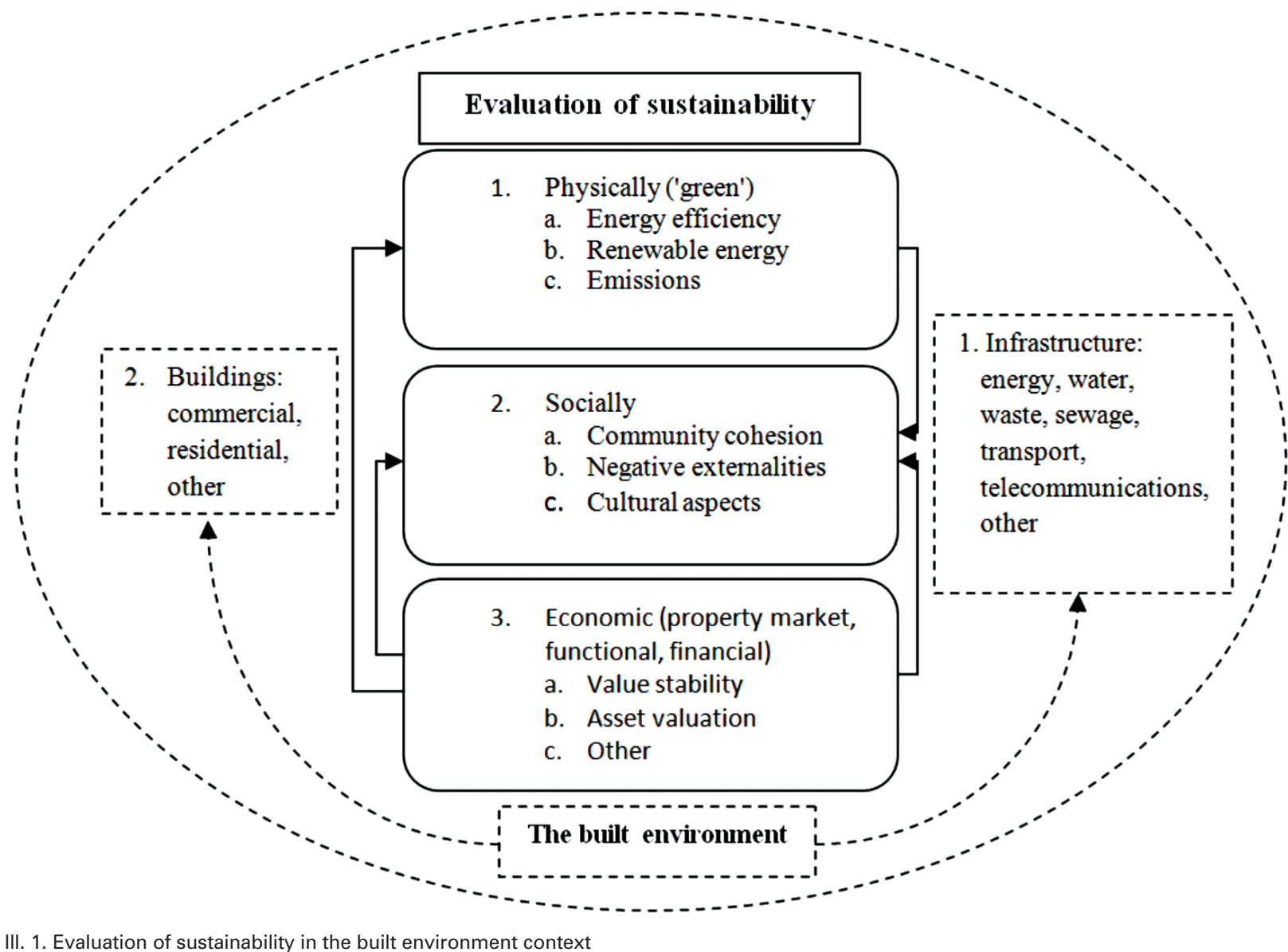

III. 2. Eco-Innovation Scoreboard 2015 [2]

Average El performers

leaders

140

120

100

80

60

40

20

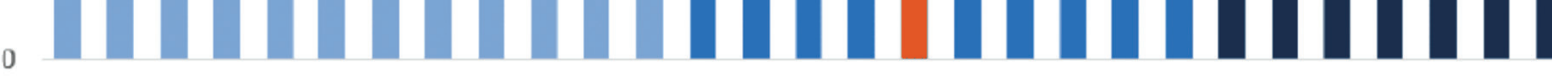

$0^{2}$ 
(financial and human resources), circular economy activities, economic aspects (urnover, exports), and contextualization of eco-innovation. We now turn to the eco-innovation performance across the $\mathrm{EU}$, in order to analyze, which countries have high versus low eco-innovation performance. In order to evaluate this specific performance across EU countries, a composite index has been developed by the Eco-Innovation Observatory [2], ill. 2.

The scoreboard aims at capturing the different aspects of The scovation by applying 16 indicators grouped into five thematic areas: (1) Eco-innovion themicicion activiles, (3) : (1) Eco-innovalion inpus, (2) eco-ine efficiency outcomes, and (5) socio-economic outcomes. Maximum perfore score was 192. In order to assess circular economy

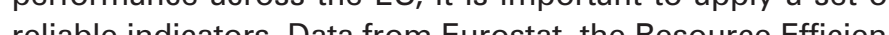
reliable indicators. Data from Eurostat, the Resource Efficiency Scoreboard and ha Raw Materials Scoreboard all contain relevant indicators and analysis, which are useful for tracking progress

\section{Green sustainability in Slovenia}

Since sustainable development of a country or a region has received more and more attention recently, many countries and regions have implemented policies to ensure or protect sustainable development. An assessment of different initiatives and policies put forward by the European Commission to promote a more sustainable economy shows that environmental policies, in particular those related to renewable energy and climate change, mainly trigger creation of green jobs. The EU also acknowledges that greening the econo$\mathrm{my}$ is a multidimensional challenge and therefore must be addressed through cross-cutting measures at the sectoral level that include targeted economic, employment and skills development policies along with industrial development, innovation and competitiveness policies.

Hitherto, Slovenia did not adopt any specific (green) legislation for green sectors. As far as green economy based on net savings (effects) of the natural resources, all industry and other

sectors of national economy are engaged here. All needed legislation adopted for those sectors is in force also for green sectors. In Slovenia, there are also two tripartite social dialogue structures that are relevant to green issues: the Council for Sustainable Development and the Interservice Group on Climate Change. Slovenian Industrial Policy (SIP) as a backdrop aim to improve the business environment refers to 10 areas of measures, environment refers to of the concept of corporate social responsibility [13]. Another important area is strengthening is the key to expanding productivity, which is the key to expanding productivity, employties for the long term development of indurity ties for the long-term development of industry. From our integral perspective, as we have now seen, we would argue that not only is a mora economic core understated in the above SIP analysis, but nature and community (southern) and culture and spirituality (eastern) should be more strongly emphasized. However, once the SIP moves onto its "priority areas" there is a integral shift in orientation toward a more overtly "green" perspective.

The "green" perspective is systematically elaborated through searching new sources of growth that are represented primarily by responses to social challenges with the introduction of a new paradigm of development, resulting from concepts of green growth (OECD), the green economy (UNEP) and a materially-efficient and low carbon society (EC), which are based on improving efficiency (energy, material, environmental and social) instead of relying on increasing consumption of space raw materials and energy Definition of priority areas is based on social challenges, Table 1 .

Table 1. SIP priority areas [13

\begin{tabular}{|c|c|c|}
\hline Challenge & Priority technology areas & Key industrial sectors \\
\hline $\begin{array}{l}\text { Environmental and en- } \\
\text { ergy challenge and the } \\
\text { efficient use of natural } \\
\text { resources based on sus- } \\
\text { tainable production and } \\
\text { consumption }\end{array}$ & $\begin{array}{l}\text { Environmental technologies (technologies } \\
\text { for the efficient use of energy, including the } \\
\text { economical use of energy, renewable energy } \\
\text { technologies, technologies for increasing } \\
\text { material efficiency etc.) }\end{array}$ & $\begin{array}{l}\text { Energetics / "Smart" systems Sustainable } \\
\text { construction Manufacturing (especially wood- } \\
\text { processing, metal and electrical industry and } \\
\text { electronics) } \\
\text { Chemical and process industry }\end{array}$ \\
\hline Sustainable mobility & Technologies for sustainable mobility & Automotive industry \\
\hline $\begin{array}{l}\text { Food, health and aging } \\
\text { population }\end{array}$ & $\begin{array}{l}\text { Biotechnology and other challenge-related } \\
\text { technologies }\end{array}$ & \begin{tabular}{|l|} 
Pharmaceutical industry \\
Food-processing industry and sustainable \\
food production \\
Sustainable tourism
\end{tabular} \\
\hline $\begin{array}{l}\text { Potential KET - Key En- } \\
\text { abling Technologies }\end{array}$ & $\begin{array}{l}\text { Nanotechnology, micro- and nanoelectron- } \\
\text { ics, photonics, biotechnology, advanced ma- } \\
\text { terials, advanced manufacturing and process } \\
\text { technologies }\end{array}$ & $\begin{array}{l}\text { ICT } \\
\text { Electrical industry and electronics New materi- } \\
\text { als } \\
\text { Metal-processing industry, engineering and } \\
\text { tool-making }\end{array}$ \\
\hline
\end{tabular}

Table 2. National development objectives to year 2020 [14]

\begin{tabular}{|l|l|l|l|}
\hline \multicolumn{1}{|c|}{ Priority } & \multicolumn{1}{|c|}{ Smart growth } & \multicolumn{1}{c|}{ Inclusive growth } & \multicolumn{1}{c|}{ Green growth } \\
\hline National objectives & $3 \%$ of GDP for R\&D & $\begin{array}{l}75 \% \text { of the economically ac- } \\
\text { tive population }\end{array}$ & $\begin{array}{l}20-20-20 \text { Environmental ob- } \\
\text { jectives }\end{array}$ \\
\cline { 2 - 4 } & $\begin{array}{l}5 \% \text { of school leavers and } \\
4 \% \text { of tertiary educated }\end{array}$ & 40 000 people out of poverty & \\
\hline Development policies & $\begin{array}{l}01 \text { Promoting Entrepreneur- } \\
\text { ship and Competitiveness } \\
\text { 02 Higher Education, Sci- }\end{array}$ & $\begin{array}{l}03 \text { Labor Market } \\
\text { ence, Technology and Infor- } \\
\text { mation Sociaty } \\
\text { 04 Education and Sport } \\
\text { 05 Culture }\end{array}$ & $\begin{array}{l}06 \text { Transport and Infrastruc- } \\
\text { ture } \\
07 \text { Energetic } \\
09 \text { Environmental and Spatial } \\
\text { Policy }\end{array}$ \\
\hline
\end{tabular}

To overcome obstacles and to achieve common goals of the EU 2020, Slovenia set the following national targets for 2020 So enter (incorporated and taken into account) in Slovenia's to enter (incorporated and taken into acco Environmental change itself and policy efforts aimed at Environ orer markets: they affect how and what is prods on the labor markets: they affect how and what is produced and how work is organized. The dynamics of labor market outcomes are complex and difficult to predict [7]. Policies almed at greening the economy might imply some degree of labor reallocation. In turn, this require appropriate labor market policies that address mismatches between the demand and supply of employment and skills, ensure that the transitions are fair for all, and foster the direct and indirect creation of jobs. Localities that have specialized in what will eventually become declining sectors (e.g. fossil fuel production) will ace the challenge of developing new specializations. Gree growth will provide new opportunities for local economic development initiatives. Some green technologies may in tially have a higher than average labor intensity, differences in labor intensity are likely to diminish over time once initia investments have been made, and new green technologies mature and become more productive, as is the case with all type of industrial sectors. It is crucial to take all these factors into account to develop economic policies in Europe that maximize both environmental benefits and quality job creation and also minimize negative effects.

Most of the new green jobs in the EU and Slovenia as well, generally occur in small and medium-sized enterprises (SMEs), as demonstrated by [15], which also shows that the (SMEs), as dero ling with the prober of the crisis, and party because dealing wis the cor labor in Slovenia winin the framework of the reseach projec sy Gren jo in Sloven a jo Green jobs in Slovenia are not systematically monitored and are not defined. Most green jobs in Slovenia caused by only five factors: renewable energy, energy-eficient construction, waste collection and waste water management, organic farming, and public transport. Nowadays, more and more students are educating and training for green jobs career. Number of narrowly defined green jobs number in Slovenia is very low. Green jobs in total are about 7.250, what present just $1 \%$ of total employment, number of widely-defined green jobs but relatively comparable with other developed countries is $2 \%$ of total employment. A positive growth rate of general employment in Slovenia is indicated and has to be considered for future green jobs evolution [16]. Majority of the new green jobs are generated in sectors such as alternative energy sources, construction, centered primarily in the construction of energy efficient buildings (increase energy efficiency), transportation both in terms of car production to alternative energy sources, as well as an improvement in fuel efficiency, production and recycling eco-friendly products and agriculture and forestry, especially in the direction of sustainable development [15]. It is worth to highlight in this context.

Gradual shift in the greening of industries as part of the corporate restructuring will result in even greater demands for greater multidisciplinary nature of jobs, employers are looking for workers is the transversal competences. Such skills can be applied everywhere in the working process: strategic planning, leadership, management skills, communication, and counseling for end-users, coordination, risk analysis, adaptation and transfer of knowledge [15].

Because of the high initial costs, uncertain financial benefits and repayment of longter investments in green technology, Governments have a key role in promoting changes in bethicr or attitude towards environmes illy friendly technogies and processes,

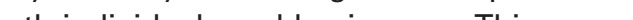
be and obstacs, but also by providing effecive incer intives reand use of also influence the development prove resource efficiency or energy pro- 
duction to sustainable levels, reducing waste and increasing the use of renewable energy sources that do not pollute the environment. In most countries, including Slovenia, regulations are also major factor of the promotion of eco-innovation $(35 \%)$, followed by market demand from customers $(30 \%)$ while $10 \%$ present fiscal incentives [17].

At national level, the most important green jobs sectors are Renewable energy (RE) and the Energy efficiency and construction. In total, 3.375 green jobs in RE sectors are indiconin Slovenia in 2016 with adding of construction are indicated number of 7.250 green jobs are in total considering a total number of 7.250 green jobs are in total considering a pure de 15.000 gren jobs are generated acoss the secto a total of 15.000 gren jobs 50.000 green oriented jobs in sustainable forestry and wood gement, building and construction, and social entrepreneurship [16, 18].

rship $[16,18]$.
There are quite a number of reports available about job creation potential result of a more ambitious transition towards renewable energy production. A good example is the "A 100\% Renewable Energy Vision for the European Union" report, the European Renewable Energy Council proposed a pathway to achieve $100 \%$ renewable in the energy sector Considering that a target of $45 \%$ renewable energy in final energy consumption in 2030 is met, this would provide an annual average growth rate of about $6 \%$ on 2020. If a target of $100 \%$ renewable energy by 2050 was followed, this constitutes an average annual increase of gross employment of $36 \%$ and $30 \%$ respectively compared to 2009 [ 19 .

In 2016, the sector of Energy Efficiency and Building is indicated as the second most important [3][20]. Energy efficiency activities are more labor-intensive than manufacturing. The leverage of public and private funding is often between ten and five to one, meaning 1 million $€$ of public money can lead to investments of between 5 and 10 million $€$. That means the creation of between 85 to 190 jobs for 1 million $€$ of public money spending [21]. The draft National energy program (NEP 2030) is based on a n en of energy efficiency to $20 \%$ by 2020 (27\% by 2030$), 25 \%$ share reduction of GHG from fub bu ve targets assume gradual increase of the share of nearly zero energy buildings (nZEB) among new and renovated buildings by $100 \%$ in 2020 and in the public sector until 2018 [19][20]. All the aforementioned targets and goals represent a significant challenge to the construction sector, particularly to the buildings field. These new boundary conditions imply necessary and swift transformation of the sector to be able to respond to strengthened demands. One of the most important tasks is to raise the level of skills and competences of the workforce for state-of-the-art implementation of nZEB practices.

However, the present situation is not advantageous. The fast growth of the construction sector lasting almost two decades ended in 2008, when collision of different internal, national and global problems led to a substantial downturn of the sector. Compared to 2008, when construction activity was at its peak with 88.000 of employees, the value of construction put in place in 2017 was more than $40 \%$ lower. With regard to buildings the value dropped by almost 30\% [16].

Number of employees in Building / Construction sector has declined from 88.000 in 2008 to 53.000 in 2013 , but in last year number of employees increased to 55.000 , of which than half $(57,9 \%)$ employes perform specia lized contruction activities. Employmeciathe construction ma $8 \%$ of sector marey $8 \%$ of total erployment in Slovenia. no longer, significanty changed the position no longer, significantly changed the position of the industry in the national economy and its ability to implement complex projects; it is also influenced by the structure of workers, including their actual qualifications [16]. Future perspectives in Energy Efficiency and construction are oriented to $[10,19,20,22]$ : national strategies in the construction secto are aimed at achieving the EU's objectives in the field of energy efficiency, renewables and emissions 20-20-20 to 2020

existing system of professional qualifications is not designed to provide or does not provide all the necessary content according to emerging needs;

therefore the current skills and competences of construction workforce largely do not satisfy the procedural requirements of nearly zero energy building;

the capacity of the construction sector needs upgrading to cope with new challenges :

an essential part of this transformation is to be an essential part of this transformation is to be acquition eficien, and by increasing the to energy skilled labor; and

to achieve this it is necessary to firmly participation of sector-specific national stakeholders, using the findings of the report on the status quo in order to create a good schedule (roadmap) of the definition of training needs content, objectives and time frame that corresponds to the national state.

The Chamber of Commerce for Construction has reported about 2.500 employees in gree jobs related to nZEB in 2015 and a need for acditional training and education for cumulative scale of 6800 trained employees in 2020 [19] Green Building Council of Slovenia (GBC) reported that sustainable construction in the first place means the proper choice of materials and implementation. The two most im-

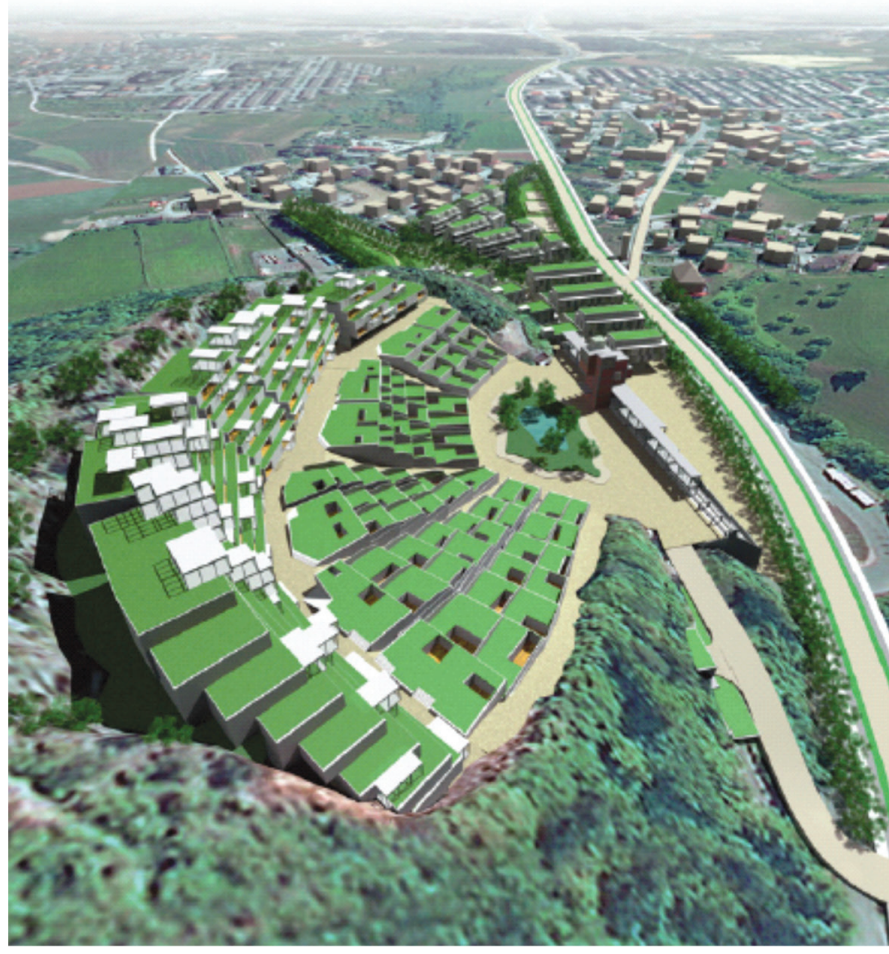

III. 3. A holistic revitalization
and the asphalt base [10]

portant aspects are: (1) The lifetime of the building, which is most influenced by the choice of materials, construction and maintenance. The Sustainable aspect introduces in the construction materials the most suitable criteria for the in criteria, and (2) Flexibility; This is reflected in the ability to satisfy different user needs [20].

of sustainable construction which GBC selects perspective of sustainable construction which living: (2) Contolling living; (2) Controll for living; (3) Accessib lity of housing to risk groups (elderly, socially deprived, etc.) (4) Psychological and social function of housing; (5) Criteria for expanding areas sultable for staying. Sustainable construction and energy and ecological efficiency improves the quality of life and the efficient use of natural resources, we also need to: (1) Energy rehabilitation of existing buildings; (2) Sustainability criteria for new buildings; (3) Rational use o natural, non-renewable resources; (4) Introduction and use of renewable energy sources; (5) Effective land use; (6) Efficien use of energy; (7) Selection of building materials according to the criteria of "buitt-in energy" (energy used for their creatio and use), reproducibility and destruction or recycling costs (8) Limit levels of water consumption as well as control ove its quality; (9) Achieving more comfortable living with less investment, especially through the path of technological innovation and innovation in service activities. Figure 3 shows a plan how to make synthesis on aforementioned criteria of degraded the abandoned quarry area and asphalt base [10]. Waste management is considered a "green" sector given its goals focused on the reduction of environmental impact as- sociated with waste treatment which presents Recycling ensures that resources remain in the economy via a closed-loop process. It contributes to a shift to a circular economy and away from a linear economy model characterized by resource depletion and waste. It also reduces virgin non-renewable resource use, directly helping decouple material use from economic growth and producing lower fonvironmental impacts. Recycling could help envis critical resorces, especially re suplies of covering a reasonaty large part of EU con-

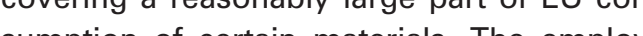
sumption of certain materials. The employment opportunitios in the recycling sector ind low skilled work in paricular, but also include medium- and high-skilled jobs, ranging from collection, materials handing and processing to manufacturing products. A annual growth of recycling of $6 \%$ is predicted for Slovenia, because of closing a num bers of small landfills and construction of full engineered waste treatment regional centers. Recycling 10.000 tons of waste needs up to 250 jobs compared with 20 to 40 jobs needed if the waste is incinerated and about 10 for landfill [23]. If a target of $50 \%$ for recycling of key materials in 2020 was met on a European level, conservative estimates suggest that the total potential in Slovenia is more than 2.500 net new jobs. In Slovenia in 2016 was in the sector of waste management employs around 6.600 people. That same year the Slovenian companies in the waste management invested more than EUR 175 million, and the waste to expenditure [16]. The net effects of waste corts waste colction and wast whe

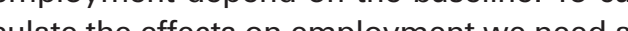
culate the effects on employment we need an cure te, for exa wo by extending the life waste, for example by extending the life of the product. Usually people argue that this would lead to an increase in the number of jobs, it would mean a shift from the secondary to the ertiary sector. This energy would be replaced by manpower. But in reality, the secondary sector is more energy intensive than the tertiary sector. The reason for this lies in the fact that the tertiary sector uses multiple means, which is also a very energy-intensive. Research also shows us that it is not clear whether it will reduce the amount of waste lead to an increase in the number of jobs. Besides the famous $3 R^{\prime}$ s (reduce, reuse, recycle), further 
essential elements of a circular economy have been brought onto the agenda. These include: refurbish, sharing / leasing, re-manufacture, recovery, and repair while reduce (in the sense of waste prevention and minimization of hazardous substances) plays also a prominent role [2]

The goal of a sustainable resource and waste management must be to ultimately achieve a transition to a fully fledged circular economy within this century [2], i.e. to preserve the value of the resources and materials as long as possible, to reuse them as often as possible and, ideally, to gessible, to or as little as possible waste. The con icept includes all sectors of the economy; especial The conction of the economi essecial the this concept as far as majority of waste is generated in this sector; f rage and consumption, as well as the disposal or recycling. Through the closing of loops waste shal becc again (so-called "second-sourcing") [20].

One important mase far as public procurement presents $16 \%$ of EU GDP several institution proposed green-based public procurement $[1,19$, $20,24]$ where EC published a manual for training and education for green public procurement. EC advised member states that at least $50 \%$ of all public procurements should be green [24]. Slovenia adopted this rule since 2010 and tested EC proposed measure of Life Cycle Costing (LCC) in construction sector where all aspect of sustainability are taken into account, economic, ecological and social [20]. Green public procurement in construction sector has to be treated carefulIy, because of cross-over effects where adopting one green option might exclude or reduce value of other green options. More effective rule for assessment of green sustainability in construction was adopted not only in Slovenia, also in Germany, Finland, Norway, etc.) where a complex system and

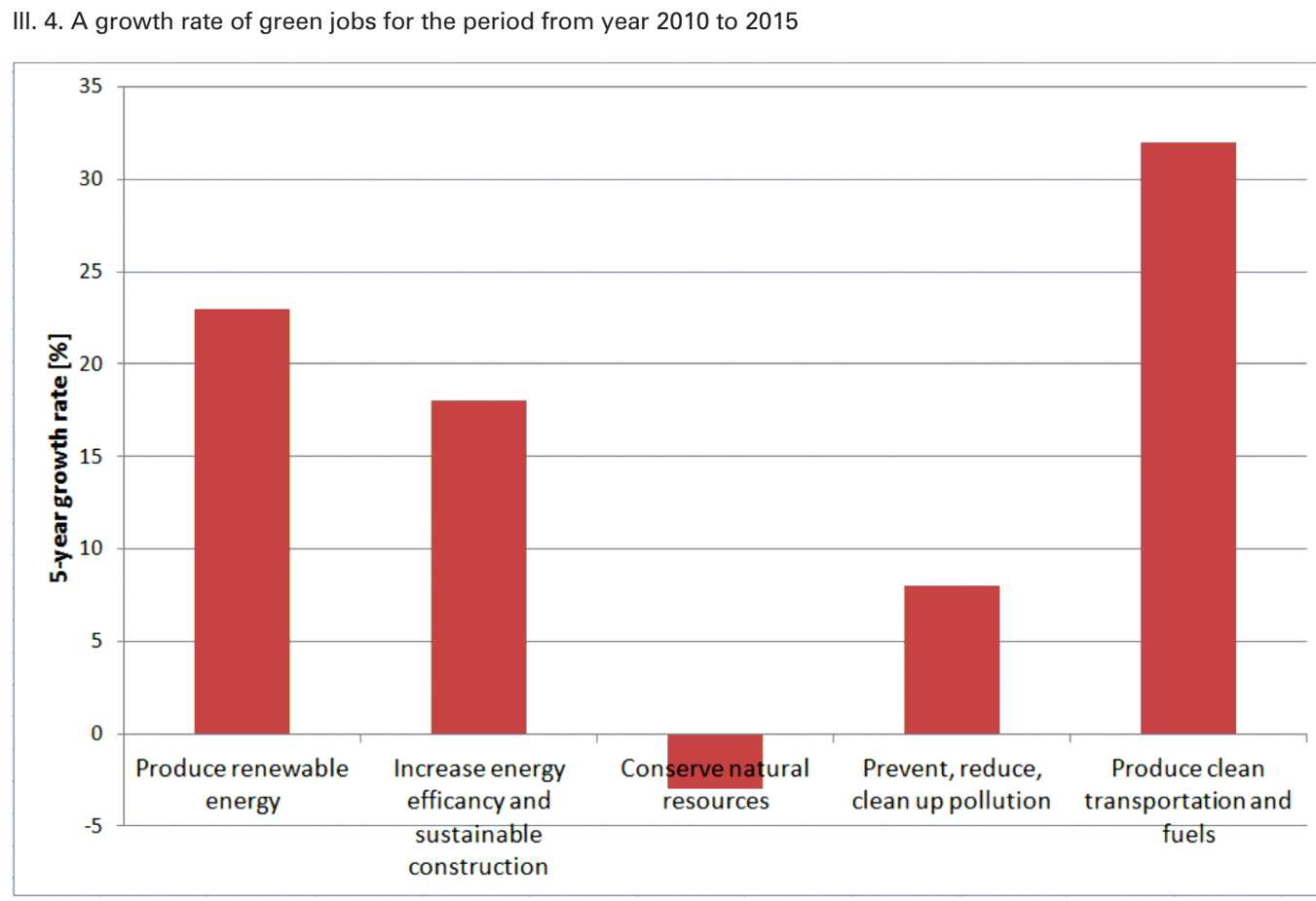

to take corrective measures. Monitoring can be carried out government insticutions, professional organizations, professional chambers or associations, depending on the program of vocational education and target groups.

Projected growth of the green sector in Slovenia for yea 2020 was moderate: Based on data in the NEP 2030 (draft National Energy Program 2030) growth of renewables in the period $2012-2020$ to $35 \%$ in 2020, while the growth of the construction sector (due to the aging of the population) in the period 2010-2020 of 12\%. For the period 2010-2020 is the period 2010-2020 (d) $12 \%$. For is thererining in the strongest geen sectors $12 \%$ [23]. In tespect To Green Industry Activities in Slovenia, from the data for the green jobs from 2010 to $2015[1,16]$, a growth rate of green jobs is indicated, ill. 4.

A trend of positive growth of green jobs is detected. Especially in the sector of transportation and transport infrastructure, renewables and sustainable construction green growth rate is positive. Only conserve of natural resources still suffers in growth, where a mutual effect of green economy is detected.

\section{Conclusion}

Green economy as new paradigm significantly affects an national economy, but efficacy of the green sectors is ambguous. To find more support for green jobs, solid strategies must be done along with a precise definition of green job nature and consequently how to measure net effects of green jobs. A huge potential for green jobs is reported in severa EU member states, but if the net effects or savings are not known, it is difficult to argue how effective the mutual influences of green economy are.

Green sustainability in construction sector is much more than only a need, because a large majority of waste is generated in this sector along with high consumption of energy and released emissions of $\mathrm{CO}_{2}$. Three aspects of sustainable green contructions should be considered, namely economic, ecological

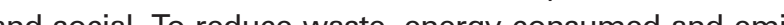
f $\mathrm{CO}_{2}$ in construction sector a concept of circular economy ropos. in culy contrib

In the case of green public procurement, it could be prescribed: (1) Requirements for meeting the criteria required for passive house, Minergie house, low energy house or any other very low energy house (the criteria are summarized, the calculation method is given, and the sign itself should not be prescribed), and (2) requirements for meeting more complex criteria for sustainable construction, given in the context of riven sustainable construction, given in the context Design), BRREAM (Building Research Establishment Environmental Assesm (Building Research Establishm (Sustainable mental Assessment Method), GBtool, SPEAR (Sustainable
Project Appraisal Routine), DGNB (German certificate for sustainable buildings)
However, the question to what extent do the green jobs really help to reduce unemployment remains unanswered. The need to calculate the net impact of green jobs on employment is indicated. It is essential that the assessment of green jobs has to combin also the social and ecological criteria.

BIBLIOGRAPHY

il. Eco-Innovation Observatory. Retrieved from: http://

2] ECo-Innovation Observatory. Policies and Practices for
coo-lnnovation Uptake and Circular Economy Transition. [3] Slovenian National Building and Civil Engineering Institute. Retrieved from: http://w sustainable-construction " Kills for green jobs". European
[4] CEDEFPP. (2010). "Skill
Synthesis Report. European Centre for the Develooment of Vocational Training, International Labour Organization
[5] World Economic Forum (2016). The Global Competitiveness Report 2016/2017. Genève. WEF. [6] I.S. Department of Commmerce Economics and Statistics
Administration. (2010). "Measuring the Green Economy." Washington.
[7] EU Employment Commission (2010). Towards a greener
labour market - The employment dimension of tackling en[8] International Labour foundataion for Sustainabie Develop-
ment (2013). Green Jobs and related policy frameworks: An

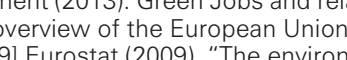

Sector. A Data Collection Handbook". Unit E3 - Environ101 Šijanec Zavrl, M. (2010). Trainostne, zele stivsion.

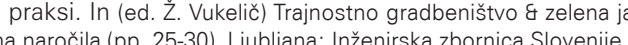

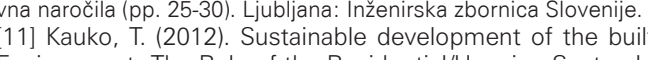
Environment: The Role of the Residential/Housing Sector. In
ed. C. Ghenail Sustainable Development - Education, Busition - Agriculture and Food Security. anijeka, Croatia: InTech.
112] Kibert, C. J. (2013). Sustainable Construction: Grees

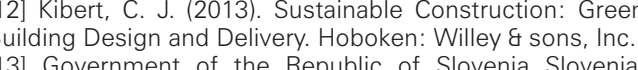
13ling Government of the Repubolice of Slovenia Slovenia
2013). Slovenian Industrial Policy - SIP. Retrieved from whw.mgrt.gov.sii

(4) Ministrstvo za gospodarstvo RS. (2013). Strategija raz-

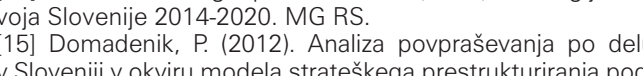
jetij, Univerza v L Lubljani, Ekonomska fakulteta. Ljubljana.
[16] Statistični urad RS. (2017). Statistični letopis 2016. Ljubljana. [17] OECD. (2017). OECD: Science, Technology and Industry Scoreboard 2015. Retrieved from http://www.oecd.org/s [18] Premuzič, A. A. (2016). Geografija in zelena delovna mesta
v Sloveniji. Magistrsko delo. Maribor: Univerza v Mariboru.

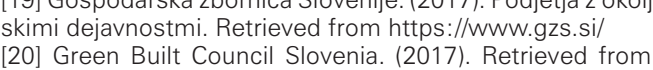

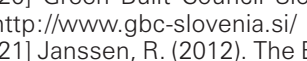

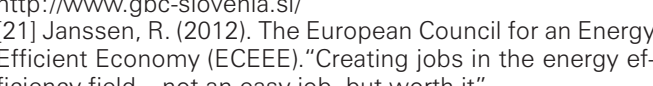
22] Zvezno ministrstrtyo za promet, gradbeništto in razvo

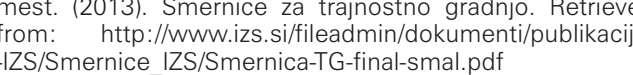
[2S/Smernice IZS/Smernica-T-G-inal-smal.pdf
[23] EC Eurostat. (2017). Retrieved from http://epp. eurostat ec.europa.eu/portal/page/portal//eurostathomel. EC.
[24] European Commision EC: Training toolkit on GP. Re-

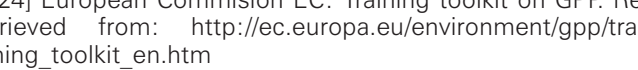

